\title{
EFEITO DA SUPLEMENTAÇÃO DIETÉTICA DE ARGININA NA CICATRIZAÇÃO DAS ANASTOMOSES COLÔNICAS EM RATOS
}

\section{Effects of oral arginine supplementation on the healing of colonic anastomoses in rats}

\author{
Milton Pereira CORRÊA-NETO, Antonio Carlos Ligoki CAMPOS, \\ Alessandra Borges BRANCO, Jorge Eduardo Fouto MATIAS
}

\begin{abstract}
Corrêa-Neto MP, Campos ACL, Branco AB, Matias JEF. Efeito da suplementação dietética de arginina na cicatrização das anastomoses colônicas em ratos. ABCD Arq Bras Cir Dig 2009;22(1):7-14

RESUMO - Racional - A arginina, aminoácido condicionalmente essencial, participa de diversos processos fisiológicos, em particular na cicatrização e na função imune. Objetivo - Avaliar o efeito da suplementação por via oral da arginina na cicatrização colônica em ratos. Método - Foram utilizados 47 ratos Wistar machos, adultos, com peso médio de 345,45 $\pm 8,35 \mathrm{~g}$, alocados em gaiolas coletivas em grupos cinco ou seis animais. Todos receberam água e ração ad libitum, pesados a cada dois dias e randomizados para receberem por gavagem suplementação com arginina a 10\% (grupo ARG) ou solução de aminoácidos a $10 \%$ (grupo AA) de forma isovolumétrica, isocalórica e isonitrogenada $(1,5 \mathrm{~g} / \mathrm{kg} / \mathrm{dia})$ por sete dias antes do procedimento operatório e quatro após. Um terceiro grupo recebeu solução salina isotônica (grupo SSI), isovolumetricamente. Os ratos foram submetidos a duas colônicas término-terminais confeccionadas $3 \mathrm{~cm}$ distais à válvula ileocecal e outra $5 \mathrm{~cm}$ distais à primeira, em plano único com fio monofilamentar de nylon 5-0, e foram sacrificados no $5^{\circ}$ dia de pós-operatório Neste dia, as duas anastomoses foram ressecadas, sendo uma conservada em solução salina para medidas de tração e a outra enviada à anatomia patológica, para análise do colágeno (total, maduro e imaturo), e imunoistoquímica para a pesquisa de miofibroblastos e neovascularização. Foi avaliado o peso corpóreo ao longo do experimento. A análise estatística foi realizada com os testes t de Student e de Mann-Whitney. Resultados - A comparação referente ao peso nos três grupos não evidenciou diferença significativa nos pesos iniciais, mas foi observada diferença entre os finais nos grupos SSI e AA (324,7g vs. $298 \mathrm{~g}, P=0,04)$. A tensão foi significativamente maior no grupo AA quando comparado ao grupo SSI $\left(0,94 \mathrm{kgf} / \mathrm{cm}^{2}\right.$ vs $\left.0,67 \mathrm{kgf} / \mathrm{cm}^{2}, P=0,04\right)$, mas não em relação ao grupo ARG $\left(0,94 \mathrm{kgf} / \mathrm{cm}^{2}\right.$ vs $\left.0,70 \mathrm{kgf} / \mathrm{cm}^{2}, P=0,09\right)$. Quanto à força máxima de tração observou-se diferença significativa entre o grupo AA e o grupo SSI $(0,18 \mathrm{kgf}$ vs $0,13 \mathrm{kgf}, P=0,04)$ mas não em relação ao grupo ARG $(0,18 \mathrm{kgf}$ vs $0,14 \mathrm{kgf}, P=0,08)$. A força de ruptura total evidenciou valor significativamente maior para o grupo AA quando comparado ao grupo ARG ( $0,10 \mathrm{kgf}$ vs $0,06 \mathrm{kgf}, P=0,05)$, mas não em relação ao grupo SSI $(0,10 \mathrm{kgf}$ vs $0,09 \mathrm{kgf}, P=0,54)$. Não foi observada diferença significativa quanto à concentração dos colágenos subtipo I e III e nem do índice de maturação de colágeno nos três grupos. Não foi observada também diferença significativa em relação à contagem de vasos sanguíneos ou miofibroblastos pela imunoistoquímica entre os três grupos. Conclusão - A administração de solução contendo 20 aminoácidos se mostrou mais efetiva do que a administração isolada de arginina nas provas de tração das anastomoses colônicas. DESCRITORES - Arginina. Cicatrização. Tensiometria. Colágeno. Angiogênese.
\end{abstract}

\section{INTRODUÇÃO}

Cicatrização adequada é considerada fundamental para o sucesso de qualquer intervenção cirúrgica, e uma falha neste processo pode levar à deiscências das suturas e graves consequências. A medida em que o processo fisiológico da cicatrização tornou-se progressivamente compreendido, fatores que influenciam este processo foram sendo descobertos e avaliados.

Falhas nas anastomoses intestinais resultam em deiscências e fístulas, associadas a alta morbi-mortalidade. Já foram bem identificadas causas locais e sistêmicas que aumentam os riscos de deiscências anstomóticas. Os principais fatores locais são a realização de anastomoses sem tensão, com boa vascularização, ausência de infecção, boa coaptação dos bordos da ferida e inclusão da submucosa

Trabalho realizado no Laboratório de Cirurgia Experimental do Programa de Pós-Graduação em Clínica Cirúrgica da Universidade Federal do Parná, Curitiba, Brasil

Correspondência: Antonio Carlos L. Campos, e-mail: accampos@ufpr.br nos pontos, por ser esta camada rica em colágeno ${ }^{9,14}$.

Além dos locais, a influência de fatores sistêmicos sobre o processo é relevante. A presença de desnutrição, o uso de anti-inflamatórios hormonais e não-hormonais e de anti-neoplásicos e a radiação ionizante influenciam negativamente a cicatrização das anastomoses, enquanto o uso judicioso de nutrição perioperatória, especialmente com dietas imunomoduladoras ou suplementos dietéticos podem aumentar a resistência tênsil das anastomoses ${ }^{3,5,8,33,39}$.

Em face à dificuldade em estudar tais mecanismos de ação em condições clínicas, alguns modelos de experimentação foram sendo desenvolvidos. A arginina, aminoácido semi-essencial, possui papel fundamental no metabolismo de diversos componentes do organismo humano ${ }^{36}$. Possui ação importante como substrato na síntese protéica, proliferação celular, neurotransmissão, vasodilatação, imunidade e no processo de cicatrização. É precursora do óxido nítrico, creatina fosfato, uréia, ornitina, prolina e outras moléculas. Como precursora da prolina possui papel importante na síntese da hidroxiprolina e, consequentemente, do colágeno. Em situações de estresse sua demanda aumenta e ela se torna aminoácido condicio- 
nalmente essencial, juntamente com a glutamina. Assim, sua suplementação dietética é considerada como terapia adjuvante na cicatrização das feridas ${ }^{34}$. Estudos recentes corroboram a idéia de que a suplementação com arginina associa-se a aumento na deposição de colágeno nas feridas em cicatrização, além de haver melhor resposta imune ${ }^{12,41}$.

$\mathrm{O}$ uso de produtos nutricionais enriquecidos com arginina mostrou-se efetivo em reduzir as infecções pósoperatórias e o tempo de internação. Em recente metanálise incluindo 18 estudos prospectivos e randomizados, foi detectada redução das deiscências de anastomoses ${ }^{40}$. Entretanto, como os suplementos nutricionais incluem outras substâncias além da arginina, não foi possível definir especificamente qual substância seria responsável pelo efeito obtido. Vários trabalhos demonstraram o papel da arginina no metabolismo protéico, porém existem ainda controvérsias a respeito do seu uso na suplementação dietética. Em 2008, Jones e Heyland em artigo de revisão $0^{20}$, propuseram um novo paradigma: a farmaconutrição. Constataram que o grande número de trabalhos que enfocaram a imunonutrição possuem resultados conflitantes. Argumentaram que, considerando o efeito dos diversos nutrientes ditos imunomoduladores, cada um teria suas indicações precisas e individualizadas nas diversas populações estudadas. Ao final, de acordo com este novo paradigma, propuseram a utilização de 17 nutrientes de forma isolada, dissociada do aspecto nutricional e estimularam estudos nesta direção em populações homogêneas com séries amplas, para determinação de diferenças na mortalidade. Assim, não fica claro se o efeito benéfico sobre a anastomose deva ser atribuído somente à arginina. Neste contexto, é necessário investigar se a suplementação da arginina, isoladamente, é capaz de conferir o mesmo efeito protetor que a suplementação com pool de aminoácidos.

O objetivo deste estudo foi comparar os efeitos da arginina com solução de aminoácidos nas anastomoses colônicas em ratos, em particular verificando o comportamento do peso ao longo do experimento, a força de tração das anastomoses, o seu efeito nos aspectos histológicos de angiogênese e proliferação de miofibroblastos)

\section{MÉTODO}

Foram utilizados 47 ratos Wistar (Rattus norvegigus albinus, Rodentia mammalia), machos, adultos, provenientes do biotério do Instituto de Tecnologia do Paraná de Curitiba, PR (15 animais) e do biotério da Fundação Universidade do Vale do Itajaí em Itajaí, SC (32 animais). Foram alocados em caixas de polipropileno forradas com serragem em grupos de cinco ou seis animais e, após período de aclimatação de sete dias, apresentavam peso médio de 345,45 $\pm 8,35$ gramas. Receberam água ad libitum e ração para ratos. As condições ambientais do laboratório foram mantidas eletronicamente para temperatura média de $22^{\circ} \mathrm{C}$ e ciclo claro-escuro de 12 horas.

A suplementação dietética foi realizada utilizando-se solução salina isotônica, solução de aminoácidos (Aminoplasmal L 10-A sem carboidratos e sem eletrólitos B. Braun,
São Paulo, SP) e solução a 10\% e L-Arginina (Arginina ${ }^{\circledR}$, Ajinomoto Interamericana do Brasil, São Paulo, SP). A suplementação de arginina ou do pool de aminoácidos foi isocalórica e isovolumétrica em doses de $1,5 \mathrm{~g} / \mathrm{kg} / \mathrm{dia}$.

Após sete dias de aclimatação, os animais foram pesados e divididos aleatoriamente em três grupos de acordo com o tipo de suplementação dietética. Diariamente eles foram sedados por inalação de éter etílico comercial em sistema fechado de campânula para receberem SSI, ARG ou o pool de AA por gavagem, por sonda oro-gástrica $8 \mathrm{~F}$ de $10 \mathrm{~cm}$ de extensão e $2 \mathrm{~mm}$ de diâmetro interno. A cada dois dias, nos dias do procedimento cirúrgico e no sacrifício também foram pesados. $O$ peso foi utilizado para cálculo do volume a ser infundido diariamente como suplemento dietético e também para o cálculo da dose de anestésico a ser administrada.

Todos os ratos receberam ração e água ad libitum durante todo o experimento. O grupo AA $(n=15)$ recebeu suplementação com aminoácidos, a $10 \%$ na dose de $1,5 \mathrm{~g} /$ $\mathrm{kg} / \mathrm{dia}$, injetada em dose única diária por sete dias antes do procedimento cirúrgico e no pós-operatório por cinco dias.

O grupo ARG $(n=16)$ recebeu suplementação com arginina a $10 \%$ também na dose de $1,5 \mathrm{~g} / \mathrm{kg} / \mathrm{dia}$, injetada como o grupo AA.

O grupo SSI $(n=16)$ recebeu soro fisiológico em dose isovolumétrica por sonda, também diariamente.

Todos os animais foram submetidos a jejum de 12 horas prévias ao procedimento cirúrgico. A anestesia foi inalatória com éter etílico comercial em sistema fechado de campânula e, para manutenção do plano anestésico foram utilizados cloridrato de cetamina a $10 \%$ na dose de $50 \mathrm{mg} / \mathrm{kg}$ de peso e cloridrato de xilazina a $\%$ na dose de $10 \mathrm{mg} / \mathrm{kg}$ de peso ambos por via intra-muscular, aplicados no músculo quadríceps e complementação com éter etílico em sistema aberto.

Após indução anestésica os animais foram pesados, complementada a anestesia, realizada a tricotomia abdominal ampla e fixados à mesa cirúrgica com elásticos, com os membros em extensão. Foram utilizados instrumentos cirúrgicos limpos, porém não esterilizados. $\mathrm{O}$ acesso à cavidade abdominal foi obtido através de incisão na linha mediana do abdome de cerca de $4 \mathrm{~cm}$. Uma vez identificado o cólon, este foi seccionado a $3 \mathrm{~cm}$ da válvula íleo-cecal e novamente a $5 \mathrm{~cm}$ distalmente à primeira secção. As anastomoses foram confeccionadas término-terminais, em plano único com pontos separados de fio monofilamentar de nylon 5-0. O fechamento da cavidade abdominal foi realizado em dois planos (sero-muscular e pele) utilizandose de fio monofilamentar.

Após a recuperação anestésica cada animal foi colocado novamente em sua caixa e liberada água e ração após 12 horas de jejum. Foi realizada analgesia pós-operatória com dipirona por via oral na dose de $20 \mathrm{mg} / \mathrm{kg}$ de peso.

Os animais foram sacrificados após cinco dias de pós-operatório com inalação em sistema fechado com campânula de dose letal de éter sulfúrico comercial. Foi então realizada laparotomia pela incisão prévia e, após inspeção da cavidade peritoneal, procedeu-se à retirada 
de dois segmentos do cólon, de cerca de $5 \mathrm{~cm}$ cada, contendo as anastomoses. Os dois espécimes cirúrgicos foram conservados em solução salina isotônica e formalina a 10 $\%$ para estudo de tração computadorizada e histológico, respectivamente. Os animais nos quais ocorreu o rompimento fora da linha de anastomose do segmento colônico durante o teste de tração, bem como os que evoluíram a óbito durante o experimento foram excluídos.

Todos os animais que morreram durante o estudo, apesar de não serem incluídos na análise estatística dos parâmetros analisados, foram examinados para evidenciação da causa da morte.

A avaliação da força de tração e de ruptura da anastomose colônica foi realizada no Laboratório de Cirurgia Experimental do Programa de Pós-Graduação em Clínica Cirúrgica da Universidade Federal do Paraná. Para avaliação desta variável, foi utilizada máquina universal de ensaio mecânico computadorizada, da marca Emic ${ }^{\circledR}$, modelo DL-500 MF, com garras de pressão ajustável manualmente e sistema eletrônico de aquisição de dados com utilização de seu próprio software (Figura 1).

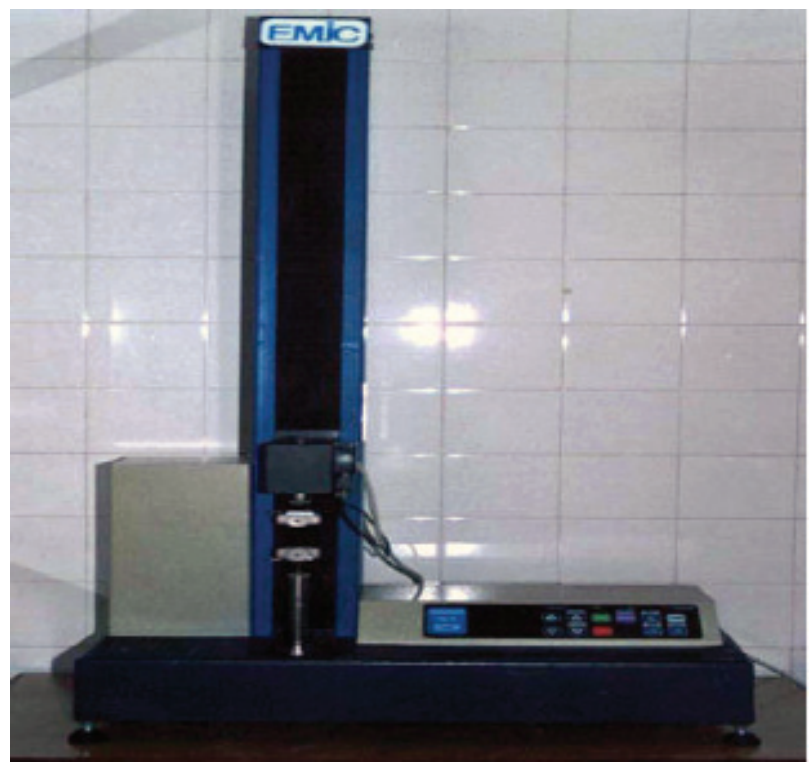

FIGURA 1 - Máquina universal de ensaio mecânico Emic $\AA$, modelo DL-500 MF

O corpo de prova de cada animal foi armazenado em frascos contendo solução salina isotônica. $\mathrm{O}$ segmento colônico, contendo a sutura em sua porção média, foi fixado em suas extremidades às presilhas com ajuste manual. Todos os testes de tração foram feitos em um intervalo máximo de uma hora após suas ressecções. A tração ocorreu com velocidade de $50 \mathrm{~mm} / \mathrm{min}$, utilizando-se carga de $10 \mathrm{~kg}$ com sensibilidade de $50 \mathrm{~g}$ e margem de erro de $0,5 \%$ até a ruptura total. A força de tração foi constantemente mensurada através do computador anexo ao sistema de presilhas.

As variáveis consideradas no estudo foram: força máxima de tração (FMT) em $\mathrm{kgf} / \mathrm{cm}^{2}$ e força de ruptura total (FRT) em kgf. A FMT foi considerada como a força máxima em que começou a haver a ruptura do tecido e a
FRT como a última força medida pelo computador, antes da separação total dos cotos colônicos.

O programa utiliza sistema de coordenadas cartesianas cujo eixo x representa a unidade "distância" e o eixo y a "força". Inicialmente o gráfico apresentou direção ascendente. No momento da ruptura inicial, ele demonstrou a mudança imediata da direção correspondendo à FMT suportada pelo corpo de prova. Durante a fase descendente do gráfico, a ruptura da peça estava em progressão, até o momento da queda de tensão ao nível zero; este ponto correspondeu à separação total dos cotos colônicos (Figura 2).

As duas variáveis de forças (FMT e FRT) foram submetidas à análise estatística.

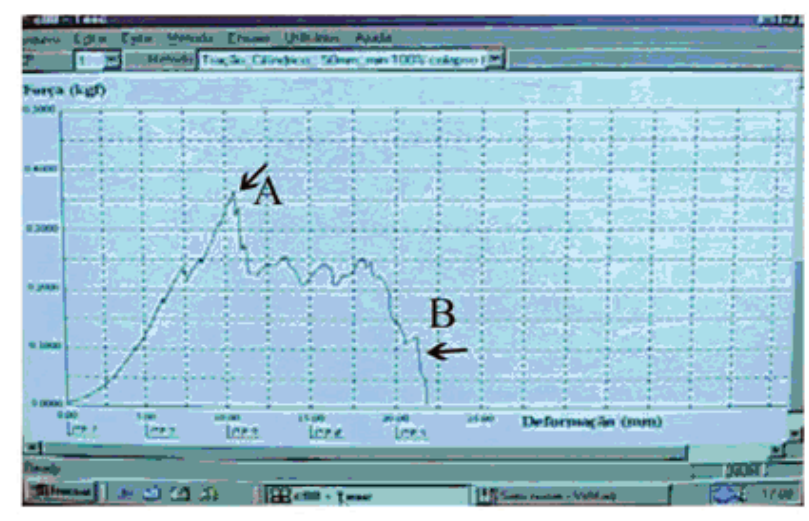

FIGURA 2 - Gráfico do estudo de tração nos corpos de prova sendo A o ponto correspondente à força máxima de tração e B ao ponto da força de ruptura total

Após a obtenção do segmento colônico de cada animal para análise histológica, o órgão foi aberto em seu sentido longitudinal na borda antimesentérica, fixado em formalina a $10 \%$ em papel filtro para manter a peça o mais aberta possível e enviado para o estudo histológico padrão para colorações hematoxilina-eosina e Masson objetivando avaliação geral, identificação da linha de sutura, e coloração imunoistoquímica, também realizada de forma padrão com o anticorpo primário anti-actina muscular lisa na diluição de 1:300 (Monoclonal de rato, Código BSB 5032, Bio-SB- Santa Barbara, EUA).

Além disso, foi realizada coloração de picro-sírius (picrosirius-red F3BA) para análise dos dois tipos de colágeno (I e III) maduro e o imaturo.

Finalmente foi realizada a análise das imagens mediante o aplicativo Optimas 6.0 para Windows. A calibração do sistema foi baseada na densidade óptica dos pontos de resolução (pixels) que formam as imagens, selecionandose o valor limite de melhor resolução. No sistema RGB (Red, Green, Blue) foram considerados valores para preto (fundo), para tons de vermelho a amarelo (colágeno tipo I) e para tons de verde (colágeno tipo III). Nos cortes histológicos analisados, determinou-se o campo microscópico sobre a linha de sutura em cinco campos distintos, obtendo-se então as médias aritméticas. Calcularam-se as percentagens das áreas ocupadas pelas fibras que continham colágeno I e III em relação à área total examinada utilizando-se software 
Image Pro Plus (Media Cybernetics, Califórnia, EUA).

A positividade da coloração imunoistoquímica foi identificada nas áreas de pigmentação acastanhada.

A avaliação do colágeno, miofibroblastos e vasos sanguíneos, foi realizada no Centro de Diagnósticos Anátomo-Patológicos de Joinville, SC. A calibragem do sistema foi baseada na densidade óptica dos pontos de resolução (pixels) que formam a imagem. Todas as lâminas foram avaliadas sob as mesmas condições de regulagem, dentro dos parâmetros exigidos pelo referido aplicativo. A percentagem de área ocupada pelo colágeno tipo I - maduro - (fibras espessas e fortemente birrefringentes, com coloração avermelhada a amarelada) e pelo tipo III - imaturo - (fibras finas e dispersas, fracamente birrefringentes, com coloração esverdeada) foi calculada para cada animal considerando-se que esta percentagem era proporcional à quantidade de cada tipo de fibra presente nos cortes histológicos. Com base nas percentagens de colágeno tipo I e tipo III criou-se o índice da maturação do colágeno - ImaC, definido como a razão entre essas percentagens. Este índice varia entre zero (percentagens do colágeno tipo $\mathrm{I}=0$ e do tipo $\mathrm{III}=100$ ) e mais infinito (percentagens de colágeno tipo $\mathrm{I}=100$ e tipo $\mathrm{III}=0$ ). Valores maiores do que 1 indicam que a percentagem de colágeno tipo I era maior do que a do colágeno tipo III.

A identificação dos miofibroblastos foi realizada contando-se as células coradas positivamente pela coloração imunoistoquímica. A contagem foi realizada analisando-se as imagens individualmente, marcando-se os miofibroblastos por meio da ferramenta Manual Tag (Figura 3).

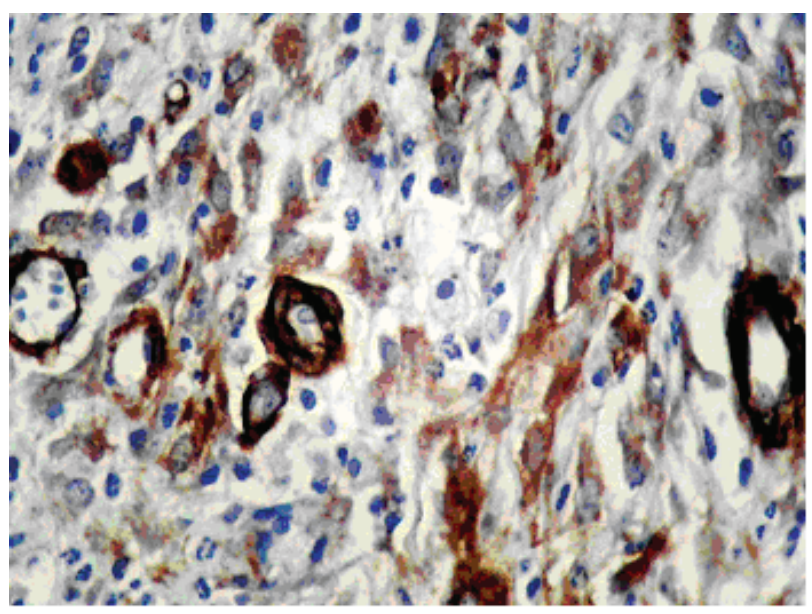

FIGURA 3 - Fotomicrografia dos miofibroblastos corados com formato poligonal, com projeções citoplasmáticas e núcleos vesiculosos (400x)

A identificação dos vasos sanguíneos foi efetuada contando-se o número de estruturas circulares coradas positivamente pelo anticorpo que revela as células contráteis da camada íntima dos vasos. A contagem foi feita na área da anastomose em aumento de 40 vezes, em três campos distintos aleatoriamente, em área de $17.726 \mu \mathrm{m} 2$, expressas em médias aritméticas (Figura 4).

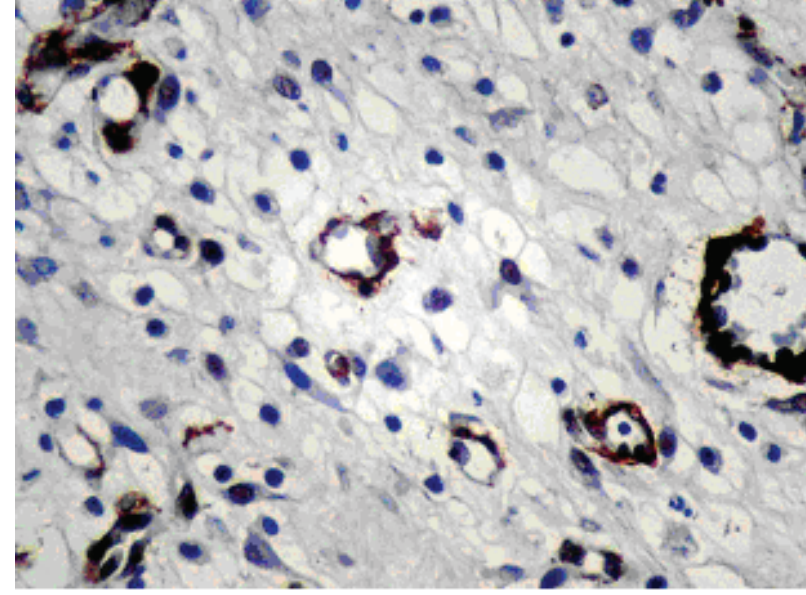

FIGURA 4 - Fotomicrografia dos vasos sanguíneos com a íntima corada em marrom revelando positividade para anti-actina muscular lisa (100x)

Após digitalização da imagem microscópica procedeu-se a análise computadorizada com o software Image Pro Plus (Media Cybernetics, Califórnia, EUA).

De acordo com a natureza dos dados analisados procedeuse o tratamento estatístico julgado adequado nos grupos SSI, AAe ARG. Observou-se o pré-requisito da distribuição normal (Gaussiana) das variáveis para a escolha do teste estatístico com os resultados expressos como média ẹ erro-padrão. Na análise paramétrica utilizou-se o teste $t$ de Student para as variáveis peso inicial e final, nas comparações dentro e entre os grupos; tensão máxima, força máxima de tração e força de ruptura total; colágenos tipos I e III, entre os grupos; contagem de neovasos e contagem de miofibroblastos entre os grupos. Na análise não-paramétrica foi utilizado o teste de Mann-Whitney para as variáveis do IMaC, entre os grupos; contagem de neovasos entre os grupos SSI vs ARG, e AA vs ARG. Em todos os testes estatísticos o nível de significância adotado foi de $P<0,05$.

\section{RESULTADOS}

Ocorreram cinco mortes de animais dos diversos grupos, sem ligação direta com o estudo e que foram excluídos das análises estatísticas.

A avaliação da média dos pesos iniciais e finais foi realizada analisando-se a diferença entre os três grupos, e não foi evidenciada diferença significativa entre eles.

A análise das médias da tração máxima entre os grupos, demonstrou significância estatística apenas entre os grupos soro e aminoácidos $(P=0,04)$, conforme demonstrado na tabela 1 .

TABELA 1 - Médias da tração máxima dos grupos SSI, AA e ARG

\begin{tabular}{llccc}
\hline Grupos & $\mathbf{n}$ & $\mathbf{m i n}-\mathbf{m a x}$ & $\mathbf{m} \pm \mathbf{e p}$ & $\mathbf{p}$ \\
\hline SSI & 10 & $0,19-1,08$ & $0,67 \pm 0,10$ & \multirow{2}{*}{0,04} \\
AA & 14 & $0,27-1,26$ & $0,94 \pm 0,08$ & \\
\hline SSI & 10 & $0,19-1,08$ & $0,67 \pm 0,10$ & \multirow{2}{*}{0,86} \\
ARG & 12 & $0,16-1,58$ & $0,70 \pm 0,11$ & \\
\hline AA & 14 & $0,27-1,26$ & $0,94 \pm 0,08$ & \multirow{2}{*}{0,09} \\
ARG & 12 & $0,16-1,58$ & $0,70 \pm 0,11$ & \\
\hline
\end{tabular}

Nota: $\mathrm{n}$ - número de animais, min-max - valores mínimo e máximo, $\mathrm{m}$ - média, ep - erro-padrão, p - nível de significância estatística 
Finalmente, a análise estatística das diferenças das médias da força de ruptura total entre os grupos demonstrou significância somente entre os grupos aminoácido e $\operatorname{arginina}(P=0,05)$.

A ruptura fora das linhas de sutura ocorreu no grupo SSI em três casos $(23,07 \%)$, um caso no grupo ARG $(14,2 \%)$ e nenhum no grupo AA.

A deposição de colágeno do tipo 1 não apresentou preponderância entre os grupos e o tipo 111 apresentou deposição semelhante nos grupos suplementados com aminoácidos e arginina (Tabela 2).

TABELA 2 - Médias do colágeno tipo III dos grupos SSI, ARG e AA

\begin{tabular}{lcccccc}
\hline GRUPOS & \multicolumn{7}{c}{ COLÁGENO TIPO III } & & \multirow{2}{*}{ p } \\
& $\mathbf{n}$ & min-max & $\mathbf{m}$ & \pm & ep & \\
\hline SSI & 12 & $8,73-63,88$ & 38,82 & \pm & 5,17 & \multirow{2}{*}{0,37} \\
AA & 14 & $16,09-72,98$ & 45,68 & \pm & 5,46 & \\
\hline SSI & 12 & $8,73-63,88$ & 38,82 & \pm & 5,17 & \multirow{2}{*}{0,65} \\
ARG & 14 & $7,05-76,13$ & 42,39 & \pm & 5,82 & \\
\hline AA & 14 & $16,09-72,98$ & 45,68 & \pm & 5,46 & \multirow{2}{*}{0,68} \\
ARG & 14 & $7,05-76,13$ & 42,39 & \pm & 5,82 & \\
\hline
\end{tabular}

Nota: $\mathrm{n}$ - número de animais, min-max - valores mínimo e máximo, m - média, ep - erro-padrão, p - nível de significância estatística

$\mathrm{O} \mathrm{IMaC}$ não apresentou diferenças estatísticas entre os três grupos.

A análise da cicatrização feita pela imunoistoquímica, avaliando a contagem de vasos sanguíneos e miofibroblastos, não apresentou diferenças estatísticas entre os grupos, conforme demonstrado nas tabelas 3 e 4 .

TABELA 3 - Médias da contagem de vasos sanguíneos dos grupos SSI,Aminoácido e Arginina

\begin{tabular}{llll}
\hline Grupos & $\mathbf{n}$ & $\mathbf{m} \pm \mathbf{e p}$ & $\mathbf{p}$ \\
\hline SSI & 12 & $4,9 \pm 0,8$ & 0,51 \\
AA & 14 & $4,3 \pm 0,5$ & \\
\hline SSI & 10 & $4,9 \pm 0,8$ & 0,48 \\
ARG & 12 & $4,4 \pm 0,5$ & \\
\hline AA & 14 & $4,3 \pm 0,5$ & 0,91 \\
ARG & 12 & $4,4 \pm 0,5$ & \\
\hline
\end{tabular}

Nota: $\mathrm{n}$ - número de animais, min-max - valores mínimo e máximo, m - média, ep - erro-padrão, p - nível de significância estatística

TABELA 4 - Médias da contagem de miofibroblastos entre os grupos Soro, Aminoácido e Arginina

\begin{tabular}{llcc}
\hline Grupos & $\mathbf{n}$ & $\mathbf{m} \pm \mathbf{e p}$ & $\mathbf{p}$ \\
\hline SSI & 12 & $34,1 \pm 5,0$ & 0,51 \\
AA & 14 & $30,5 \pm 2,7$ & \\
\hline SSI & 10 & $34,1 \pm 5,0$ & 0,55 \\
ARG & 12 & $30,6 \pm 3,2$ & \\
\hline AA & 14 & $30,5 \pm 2,7$ & 0,98 \\
ARG & 12 & $30,6 \pm 3,2$ & \\
\hline
\end{tabular}

Nota: $\mathrm{n}$ - número de animais, min-max - valores mínimo e máximo, $\mathrm{m}$ - média, ep - erro-padrão, p - nível de significância estatística

\section{DISCUSSÃO}

O rato foi escolhido como animal de experimentação devido a que ele possui regime de alimentação rudimentar - o que permite a introdução de alterações dietéticas com certa facilidade. Existe dificuldade inicial na confecção de anastomoses em estruturas de pequeno diâmetro. Apesar deste fato, após treinamento, as anastomoses foram perfeitamente exequíveis sem auxílio de instrumentos de magnificação de imagem e com relativa agilidade. A gavagem para administração da ARG, do pool de AA ou da SSI também é de fácil aprendizagem após treinamento com material adequado. Foi feita sob sedação, porém com treinamento também poderia ter sido feita sem sedação.

O aminoácido semiessencial arginina foi alvo de estudos nas últimas décadas do século passado em razão de suas ações nos mecanismos fisiológicos de cicatrização e reparação de tecidos, bem como sua participação nos mecanismos de defesa imunológica ${ }^{41}$. No processo de degradação da arginina alguns produtos destacam-se, como as poliaminas e o óxido nítrico. As primeiras são essenciais à síntese protéica como ocorre, por exemplo, na cicatrização de feridas, enquanto o último possui importância na regulação dos linfócitos $\mathrm{T}$ (em baixas doses estimula sua atividade e em altas doses provoca efeitos inibitórios nos mesmos) ${ }^{11}$.

O presente estudo avaliou o efeito da arginina na cicatrização colônica utilizando dois grupos de controle. O primeiro, consistiu na administração isovolumétrica de solução salina e, o segundo, utilizou solução de aminoácidos de forma igualmente isovolumétrica e também isonitrogenada e isocalórica. Estes controles foram fundamentais para a correta interpretação dos resultados.

O conhecimento da cicatrização intestinal tem avançado consideravelmente e existe hoje compreensão do impacto de vários fatores, locais e sistêmicos que influenciam o processo cicatricial. Ao contrário da cicatrização cutânea - na qual o progresso pode ser avaliado diariamente (em havendo uma complicação pode ser instituído tratamento precoce), a cicatrização de anastomose intestinal não pode ser visualizada. Esta particularidade deixa ao cirurgião apenas os parâmetros de bem estar evolucional do paciente para julgar o sucesso da operação ${ }^{37}$. Muito do que se sabe até agora sobre cicatrização foi justamente estudado a nível de pele e extrapolado para outros tecidos. Há particularidades metabólicas inerentes a cada órgão, que se refletem em diferentes resultados durante o processo de cicatrização. A dificuldade em se avaliar clinicamente as anastomoses colônicas justifica a necessidade de modelos experimentais que estudem o processo cicatricial no tecido em questão ${ }^{23}$.

De acordo com Hendriks et al. ${ }^{18}$, a investigação da cicatrização das anastomoses intestinais com intuito de melhorar seus resultados necessita de maneiras de quantificação. Este processo pode ser baseado em parâmetros clínicos, mecânicos, histológicos e imunoistoquímicos. A preferência é pelos três últimos.

Os parâmetros clínicos, largamente utilizados na avaliação da evolução das anastomoses intestinais, possuem menor acurácia em relação aos outros e são considerados apenas 
adjuvantes nos estudos de cicatrização, principalmente por serem subjetivos na avaliação. No presente estudo, não houve diferença na cicatrização entre os grupos quando avaliada sob o prisma clínico de evolução.

A aferição do peso é parâmetro clínico nutricional utilizado em vários estudos ${ }^{8,39}$. A desnutrição é deletéria para a cicatrização de anastomoses colônicas. Karahasanoglu et al. ${ }^{21}$ evidenciaram perda ponderal de aproximadamente $15 \%$ do peso corpóreo inicial em ratos alimentados com dieta hipoprotéica por 10 dias antes da realização de anastomose colônica. Com isso, encontraram diminuição significativa nas pressões de ruptura nas anastomoses dos animais desnutridos. Vizzotto Jr. et al. ${ }^{39}$ evidenciou perda de peso durante estudo da cicatrização de anastomoses colônicas na vigência de quimioterapia intraperitoneal. Entretanto, não houve correlação com o decréscimo da força máxima de tração ou de ruptura total, sugerindo que o fator nutricional pode não ser preponderante no prejuízo da cicatrização das anastomoses colônicas induzido pela cisplatina intraperitoneal. No presente estudo a perda ponderal ocorreu em todos os grupos ao longo do experimento, sendo maior no grupo aminoácido, menor no grupo soro e o grupo arginina apresentou resultado intermediário, sendo de significância estatística a diferença de pesos finais quando comparada a diferença entre os grupos aminoácido e soro. Convém ressaltar que a perda ponderal é fato que se repete em grupos nos quais há necessidade de manipulação com sedação para se fazer a gavagem e também o período entre o procedimento cirúrgico e o sacrifício foi relativamente curto (cinco dias).

Estudo prévio deste laboratório ${ }^{8}$, demonstrou que nos grupos de ratos sacrificados com três dias também houve também perda ponderal, ao contrário dos grupos sacrificados aos oito dias de pós-operatório. Tal fato demonstra que neste estudo a fase para o sacrifício seja talvez ainda precoce para a recuperação do trauma cirúrgico, porém a literatura sugere melhores resultados a partir do $4^{\circ}$ dia de pós-operatório.

A cicatrização ideal de uma ferida está relacionada com a proliferação fibroblástica e deposição de colágeno e outros elementos do tecido conectivo. A fibroplasia e a síntese do colágeno iniciam-se nas primeiras 24 horas do ferimento, seguindo-se em 48 a 72 horas pela migração endotelial. Ao redor do $4 .^{\circ}$ dia há a produção de fatores de crescimento que estimulam tanto a fibroplasia como a neovascularização ${ }^{26}$. A força tênsil está relacionada com a multiplicação e maturação dos fibroblastos. Segundo Harvey ${ }^{16}$, é necessário período de aproximadamente quatro dias para a maturação dos fibroblastos. No presente estudo, os intervalos utilizados para avaliar a angiogênese, formação dos miofibroblastos, deposição do colágeno e tensiometria foi cinco dias após o procedimento operatório. Da mesma forma que o parâmetro peso, os resultados de medidas tensiométricas mais significantes foram quando se compararam os grupos aminoácido e solução salina isotônica, com exceção da força de ruptura total, que mostrou maior diferença na comparação entre os grupos arginina e aminoácido.

Dados da literatura relatam que a boa cicatrização de uma ferida, com desenvolvimento de força tênsil adequada, está intimamente relacionada à proliferação e deposição do colágeno e outros elementos do tecido conectivo. A maioria dos dados disponíveis na literatura sugere que a síntese de colágeno atinge seu nível máximo entre os sete e 14 dias após a lesão, ocorrendo o pico entre $21^{\circ}$ e $28^{\circ}$ dias de evolução ${ }^{10,24,26,27}$. Os miofibroblastos são encontrados no tecido de cicatrização entre o $4^{\circ}$ e $6^{\circ}$ dias após a injúria, com maior proliferação entre o $8^{\circ}$ e $30^{\circ 7}$. No presente estudo escolheu-se $05^{\circ}$ dia para o sacrifício, pois conforme trabalhos da literatura até o $4^{\circ}$ dia pós-operatório $100 \%$ das rupturas ocorreram na linha de sutura ${ }^{19}$.

Os resultados das forças de tração demonstraram maior resistência das anastomoses nos grupos aminoácido e arginina, especialmente o primeiro. Tais resultados podem ser justificados pelo fato da solução de aminoácidos apresentar, em sua composição, todos os aminoácidos necessários para a síntese protéica, enquanto o grupo ARG recebeu somente este aminoácido, comprovando o efeito dos outros aminoácidos na cicatrização das anastomoses colônicas. A única exceção foi na força de ruptura total que demonstrou um maior valor no grupo aminoácido, seguido pelo grupo soro e depois pelo grupo arginina. A ruptura fora das linhas de anastomose ocorreu $23,07 \%$ no grupo SSI e $14,2 \%$ no arginina. Tais resultados indicam etapa mais tardia nas rupturas fora das anastomoses e consequentemente processo mais retardado nos grupos suplementados com aminoácidos e arginina, porém de melhor qualidade.

Os cortes histológicos corados pelo picrosírius permitiram detectar o tipo de colágeno. A análise computadorizada, com o desenvolvimento de softwares específicos para a determinação do percentual de área ocupada pelo tipo específico de colágeno, permitiu quantificar a deposição de cada um deles de maneira objetiva e precisa. No presente estudo, os resultados da deposição de colágeno demonstraram predominância do tipo 1 no grupo SSI e do tipo 111 no grupo aminoácidos; tais resultados fazem supor que o processo de deposição de colágeno já estivesse em fase mais adiantada ou final quando comparada com os grupos suplementados, seja com arginina ou com aminoácidos.

Para o estudo dos miofibroblastos foi realizada imunoistoquímica, utilizando-se anticorpo anti-actina muscular lisa (anti-sm), estudado pela primeira vez por Skalli et al. ${ }^{32}$, que demonstraram positividade para a identificação dessas células. Elas foram identificadas e contadas manualmente após digitalização da imagem da microscopia. Em estudo sobre a angiogênese na cicatrização de feridas, Ruiter et al. ${ }^{29}$ utilizaram como antígeno a técnica imunoistoquímica de PAL-E, que é altamente específica para endotélio de vaso sanguíneo, porém o fator VIII e o CD34 apresentaram maior sensibilidade e expressos também em arteríolas. No presente estudo, a contagem dos vasos sanguíneos foi feita por imunoistoquímica através do mesmo antígeno utilizado para a identificação dos miofibroblastos, pois a exemplo destes, células endoteliais também apresentam propriedades contráteis em sua estrutura. No presente estudo a coloração por imunoistoquímica apresentou marcação para vasos sanguíneos da mesma forma que para miofibroblastos. Os resultados mostraram maior número de vasos sanguíneos e miofibroblastos no grupo SSI que os demais, sem diferença 
entre os grupos aminoácido e arginina. Se poderia esperar maior contagem de neovasos e de miofibroblastos no grupo suplementado por AA ou ARG, uma vez que a angiogênese e a proliferação miofibroblástica são etapas importantes no processo cicatricial. Os referidos resultados podem indicar, a exemplo da análise do colágeno, que a suplementação com arginina ou aminoácidos promove processo de cicatrização mais lento, porém mais intenso, levando em última análise à melhor qualidade.

Importante ressaltar que diversos trabalhos publicados visando o estudo do efeito da arginina em ratos, foram utilizados como controle solução salina isotônica ${ }^{1,30,31,42}$, solução com outros imunutrientes, o aminoácido glicina $a^{6,15,25}$ ou água ${ }^{22}$. No presente estudo visando comparar o efeito da arginina isoladamente, empregaram-se dois controles, sendo um com solução salina isotônica e outro com solução de aminoácidos utilizada em nutrição parenteral, que inclui em sua fórmula a arginina, porém em concentração 10 vezes inferior a do grupo de estudo.

Após a coleta dos resultados, obteve-se evidências que a arginina promoveu melhora nas provas de tração e ruptura em relação ao grupo SSI, mesmo que o grupo aminoácido tenha tido maiores valores, o que se justificaria, pois na solução de aminoácidos além da arginina diversos outros aminoácidos estão presentes e consequentemente exercem seu efeito nutricional de maneira sinérgica. Da mesma forma, ao analisar-se o colágeno, evidenciou-se deposição mais precoce assim como substituição da forma imatura (tipo III) pela forma madura (tipo I) no grupo solução SSI. A análise por imunoistoquímica também evidenciou maior número de vasos sanguíneos e miofibroblastos no grupo SSI, implicando igualmente em processo de cicatrização mais acelerado, porém encerrando-se mais precocemente.

Em recente trabalho publicado ocorreu a proposta um novo paradigma: a farmaconutrição ${ }^{20}$. $\mathrm{O}$ conceito implica em indicar-se adequadamente cada imunonutriente, tais como glutamina, selênio, óleo de peixe (ácidos graxos -3) e arginina, a cada situação clínica, entre elas desnutrição, queimaduras, trauma, pacientes em estado crítico ou em síndrome de estresse respiratório agudo. Basearam sua argumentação no fato que os diversos estudos apresentados até o momento incorrem em erros metodológicos diversos, como seleção inadequada da amostra para estudo, uso de produtos para o estudo que associam diversos imunonutrientes ${ }^{2,4,13,17,28,35,38,43}$. Nesta linha de raciocínio, alguns autores estão buscando limitar o foco da amostra. Por exemplo, Waitzberg et al. ${ }^{40}$, em 2006, apresentou estudo em que incluiu apenas pacientes cirúrgicos no pré-operatório, apesar de utilizar produto com diversos imunonutrientes. Conseguiu na metanálise definir a dose a ser utilizada $(0,5$ a $1 \mathrm{~L} /$ dia $)$ de uma dieta comercial, assim como a duração da suplementação (cinco a sete dias antes do procedimento operatório). Realizou ainda um estudo de custo-efetividade e ao final recomendou a utilização da solução em casos selecionados e no período indicado.

A exemplo deste trabalho, outros estudos serão necessários para avaliação de cada um dos elementos presentes nas soluções comercialmente disponíveis e também em populações de estudo restritas.

\section{CONCLUSÃO}

A utilização da arginina promove efeitos benéficos nas anastomoses colônicas em ratos, superior ao uso de SSI, porém inferior à administração de pool de aminoácidos.

Corrêa-Neto MP, Campos ACL, Branco AB, Matias JEF. Effects of oral arginine supplementation on the healing of colonic anastomoses in rats. ABCD Arq Bras Cir Dig 2009;22(1):7-14

ABSTRACT - Background - Arginine, a conditionally essential amino acid, participates in various physiological processes, particularly in wound healing and immune function. Aim - To evaluate the effect of oral supplementation of arginine on colonic healing in rats. Methods - Forty-seven male adult Wistar rats, with an average weight of $345.45 \pm 8.35 \mathrm{~g}$ were used. They were placed in collective cages in groups five or six animals. All received water and food ad libitum, were weighed every two days and randomized to receive supplementation by gavage with a $10 \%$ arginine solution (ARG group) or an isovolumetric, isocaloric and isonitrogenous $(1,5 \mathrm{~g} / \mathrm{kg} /$ day) $10 \%$ amino acids solution (group AA) for seven days before the procedure and four after surgery. A third group received isovolumetric isotonic saline solution (group SSI). All rats were subjected to two end to end colonic anastomoses, one $3 \mathrm{~cm}$ distal to the ileocecal valve and another $5 \mathrm{~cm}$ distal from the first, in a single layer with monofilamentar nylon 5-0, and were sacrificed at 5 days post-surgery. At sacrifice, both anastomoses were resected, one was kept in a saline solution for traction measurements while the other was sent to pathology for analysis of collagen (total, mature and immature) and immunohistochemistry for the detection of myofibroblasts and neovascularization. We evaluated the body weight throughout the experiment. Statistical analysis was performed using the Student t test and Mann-Whitney test. Results - The comparison of body weight in the three groups showed no significant difference in initial weights, but a difference was observed between the groups SSI and AA in final weight (324.7 g vs. $298 \mathrm{~g}, P=0.04)$. The tension strength was significantly higher in the AA group as compared to SSI $\left(0.94 \mathrm{kgf} / \mathrm{cm}^{2} \mathrm{vs} .0 .67 \mathrm{kgf} / \mathrm{cm}^{2}, P=0.04\right)$ but not when compared to the ARG group $\left(0.94 \mathrm{kgf} / \mathrm{cm}^{2}\right.$ vs. $\left.0.70 \mathrm{kgf} / \mathrm{cm}^{2}, P=0.09\right)$. For the maximal tension strength there was a significant difference between the AA group and the SSI group ( 0.18 vs $0.13 \mathrm{kgf} \mathrm{kgf,} P=0.04)$ but not when compared to the ARG group $(0.18 \mathrm{vs} 0.14 \mathrm{kgf} \mathrm{kgf}, P=0.08)$. The total rupture strength of showed significantly higher values for the AA group as compared to the ARG group $(0.10 \mathrm{vs} 0.06 \mathrm{kgf} \mathrm{kgf}, P=0.05)$ but not when compared to the SSI group ( $0.10 \mathrm{vs} 0.09 \mathrm{kgf} \mathrm{kgf}, P=0.54)$. There was no significant difference in the concentration of collagen subtypes I and III and also no difference in the collagen maturation index in the three groups. There was also no significant difference on the number of blood vessels (angiogenesis) or myofibroblasts by immunohistochemistry among the three groups. Conclusions - The administration of a solution containing 20 amino acids was more effective than arginine alone on the healing of colonic anastomoses in rats.

HEADINGS - Arginine. Healing. Tensiometer. Collagen. Angiogenesis. 


\section{REFERÊNCIAS}

1. Arbśs MA, Ferrando JM, Vidal J, Quiles MT, Huguet P, Castells J, Segarra A, Armengol M, Schwartz S. Early effects of exogenous arginine after the implantation of prosthetic material into the rat abdominal wall. Life Sci. 2000 Oct 6;67(20):2493-512.

2. Beale RJ, Sherry T, Lei K, Campbell-Stephen L, McCook J, Smith J, Venetz W, Alteheld B, Stehle P, Schneider H. Early enteral supplementation with key pharmaconutrients improves Sequential Organ Failure Assessment score in critically ill patients with sepsis: outcome of a randomized, controlled, doubleblind trial. Crit Care Med. 2008 Jan;36(1):131-44.

3. Bonin EA, Campos AC, Coelho JC, Matias JE, Malafaia O, Jonasson TH. Effect of pantoprazole administered subcutaneously on the healing of sutured gastric incisions in rats. Eur Surg Res. 2005 Jul-Aug;37(4):250-6.

4. Calder PC. Immunonutrition in surgical and critically ill patients. Br J Nutr. 2007 Oct;98 Suppl 1:S133-9.

5. Campos FG, Mucerino DR, Waitzberg DL, Logulo AF, El Ibrahim R, Nadalin W, Habr-Gama A. Efeitos protetores da glutamina e dieta elementar na enterocolite actínica aguda: avaliação histológica. Rev Ass Med Brasil. 1994;40(3):143-9.

6. Chyun JH, Griminger P. Improvement of nitrogen retention by arginine and glycine supplementation and its relation to collagen synthesis in traumatized mature and aged rats. J Nutr. 1984 Sep;114(9):1697-704.

7. Cornelissen AM, Stoop R, Von den Hoff HW, Maltha JC, Kuijpers-Jagtman AM. Myofibroblasts and matrix components in healing palatal wounds in the rat. J Oral Pathol Med. 2000 Jan;29(1):1-7.

8. da Costa MA, Campos AC, Coelho JC, de Barros AM, Matsumoto HM. Oral glutamine and the healing of colonic anastomoses in rats. JPEN J Parenter Enteral Nutr. 2003 May-Jun;27(3):182-5.

9. Cronin K, Jackson DS, Dunphy JE. Changing bursting strength and collagen content of the healing colon. Surg Gynecol Obstet. 1968 Apr;126(4):747-53.

10. Diegelmann RF, Rothkopf LC, Cohen IK. Measurement of collagen biosynthesis during wound healing. J Surg Res. 1975 Oct;19(4):239-43.

11. Efron DT, Barbul A. Arginine and immunonutrition: a reevaluation. Nutrition. 2000 Jan;16(1):73-4.

12. Farreras N, Artigas V, Cardona D, Rius X, Trias M, González JA. Effect of early postoperative enteral immunonutrition on wound healing in patients undergoing surgery for gastric cancer. Clin Nutr. 2005 Feb;24(1):55-65.

13. Finco C, Magnanini P, Sarzo G, Vecchiato M, Luongo B, Savastano S, Bortoliero M, Barison P, Merigliano S. Prospective randomized study on perioperative enteral immunonutrition in laparoscopic colorectal surgery. Surg Endosc. 2007 Jul;21(7):1175-9.

14. Getzen LC, Roe RD, Holloway CK. Comparative study of intestinal anastomotic healing in inverted and everted closures. Surg Gynecol Obstet. 1966 Dec;123(6):1219-27.

15. Gurbuz AT, Kunzelman J, Ratzer EE. Supplemental dietary arginine accelerates intestinal mucosal regeneration and enhances bacterial clearance following radiation enteritis in rats. J Surg Res. 1998 Feb 1;74(2):149-54.

16. Harvey SC, The velocity of the growth of fibroblasts in the healing wound. Arch Surg. 1929;18(4):1227-40.

17. Helminen H, Raitanen $M$, Kellosalo J.Immunonutrition in elective gastrointestinal surgery patients. Scand J Surg. 2007;96(1):46-50.

18. Hendriks T, Mastboom WJ. Healing of experimental intestinal anastomoses. Parameters for repair. Dis Colon Rectum. 1990 Oct;33(10):891-901.

19. Ikeuchi D, Onodera H, Aung T, Kan S, Kawamoto K, Imamura M, Maetani $\mathrm{S}$. Correlation of tensile strength with bursting pressure in the evaluation of intestinal anastomosis. Dig Surg. 1999;16(6):478-85

20. Jones NE, Heyland DK. Pharmaconutrition: a new emerging paradigm. Curr Opin Gastroenterol. 2008 Mar;24(2):215-22.

21. Karahasanoglu T, Altinli E, Hamzaoglu I, Paksoy M, Yeşildere T, Alemdaroglu $\mathrm{K}$. Effect of growth hormone treatment on the healing of left colonic anastomoses in protein-malnourished rats. Br J Surg. 1998 Jul;85(7):931-3.
22. Kirk SJ, Regan MC, Wasserkrug HL, Sodeyama M, Barbul A. Arginine enhances T-cell responses in athymic nude mice. JPEN J Parenter Enteral Nutr. 1992 Sep-Oct;16(5):429-32.

23. Koruda MJ, Rolandelli RH. Experimental studies on the healing of colonic anastomoses. J Surg Res. 1990 May;48(5):504-15.

24. Madden JW, Peacock EE Jr. Studies on the biology of collagen during wound healing. I. Rate of collagen synthesis and deposition in cutaneous wounds of the rat. Surgery. 1968 Jul;64(1):288-94.

25. Nirgiotis JG, Hennessey PJ, Andrassy RJ. The effects of an arginine-free enteral diet on wound healing and immune function in the postsurgical rat. J Pediatr Surg. 1991 Aug;26(8):936-41.

26. Orgill D, Demling RH. Current concepts and approaches to wound healing. Crit Care Med. 1988 Sep;16(9):899-908.

27. Peacock EE. Some aspects of fibrinogenesis during the healing of primary and secondary wounds. Surg Gynecol Obstet. 1962;115(4):408-14

28. Petrov MS, Atduev VA, Zagainov VE. Advanced enteral therapy in acute pancreatitis: is there a room for immunonutrition? A meta-analysis. Int J Surg. 2008 Apr;6(2):119-24.

29. Ruiter DJ, Schlingemann RO, Westphal JR, Denijn M, Rietveld FJ, De Waal RM. Angiogenesis in wound healing and tumor metastasis. Behring Inst Mitt. 1993 Aug;(92):258-72.

30. Shi HP, Most D, Efron DT, Witte MB, Barbul A. Supplemental L-arginine enhances wound healing in diabetic rats. Wound Repair Regen. 2003 MayJun;11(3):198-203.

31. Shi HP, Wang SM, Zhang GX, Zhang YJ, Barbul A. Supplemental L-arginine enhances wound healing following trauma/hemorrhagic shock. Wound Repair Regen. 2007 Jan-Feb;15(1):66-70.

32. Skalli O, Ropraz P, Trzeciak A, Benzonana G, Gillessen D, Gabbiani G. A monoclonal antibody against smooth muscle actin: a nem probe for smooth muscle differentiation. J Cell Biol. 1988;103(6):2787-96.

33. Skinovsky J, Malafaia O, Ioshii SO, Campos ACL. Nicotina interfere na cicatrização de anastomoses do intestino delgado em ratos. Arq Bras Cir Dig. 2001;14(4):151-4.

34. Stechmiller JK, Childress B, Cowan L. Arginine supplementation and wound healing. Nutr Clin Pract. 2005 Feb;20(1):52-61.

35. Takeuchi H, Ikeuchi S, Kawaguchi Y, Kitagawa Y, Isobe Y, Kubochi K, Kitajima $\mathrm{M}$, Matsumoto S. Clinical significance of perioperative immunonutrition for patients with esophageal cancer. World J Surg. 2007 Nov;31(11):2160-7.

36. Thompson C, Fuhrman MP. Nutrients and wound healing: still searching for the magic bullet. Nutr Clin Pract. 2005 Jun;20(3):331-47.

37. Thornton FJ, Barbul A. Healing in the gastrointestinal tract. Surg Clin North Am. 1997 Jun;77(3):549-73.

38. Tsujinaka T, Hirao M, Fujitani K, Mishima H, Ikenaga M, Sawamura T, Kurata M. Effect of preoperative immunonutrition on body composition in patients undergoing abdominal cancer surgery. Surg Today. 2007;37(2):118-21.

39. Vizzotto AO Jr.; Noronha L, Scheffel DLH, Campos ACL. Effect of the cisplatin applied before and after the surgical procedure on the healing of colonic anastomoses in rats. J Bras Pathol Med Lab. 2003;39(2):143-9.

40. Waitzberg DL, Saito H, Plank LD, Jamieson GG, Jagannath P, Hwang TL, Mijares JM, Bihari D. Postsurgical infections are reduced with specialized nutrition support. World J Surg. 2006 Aug;30(8):1592-604.

41. Witte MB, Barbul A. Arginine physiology and its implication for wound healing. Wound Repair Regen. 2003 Nov-Dec;11(6):419-23.

42. Witte MB, Thornton FJ, Tantry U, Barbul A. L-Arginine supplementation enhances diabetic wound healing: involvement of the nitric oxide synthase and arginase pathways. Metabolism. 2002 Oct;51(10):1269-73.

43. Zheng Y, Li F, Qi B, Luo B, Sun H, Liu S, Wu X. Application of perioperative immunonutrition for gastrointestinal surgery: a meta-analysis of randomized controlled trials. Asia Pac J Clin Nutr. 2007;16 Suppl 1:253-7.

Fonte de financiamento: não há Conflito de interesse: não há Recebido para publicação: 29/06/2008 Aceito para publicação: 13/10/2008 